\title{
Undergraduate Students' Use of Time: A Classroom Investigation
}

\section{Barbara E. Brittingham}

The University of Rhode Island

Conducting a classroom research project gave me a new kind of opportunity to learn through teaching. Until recently, most of what I learned through teaching was either about subject matter (e.g., gaining a new interpretive perspective on a problem from a student) or about pedagogical knowledge (e.g., how particular aspects of a course should be organized and presented most effectively). Classroom research gave me the opportunity to learn about learning from students. Thus, as I approached the classroom research project, two things seemed to distinguish it from more traditional ways I have learned from students: 1) in conducting classroom research I would focus on students' learning (as opposed to subject matter knowledge or to my skills at teaching); and 2) my own learning would be the result of fairly systematic efforts rather than serendipitous occurrence. While classroom research may be less formal and more applied than much other research that faculty members conduct, as with all research it begins with a question to be addressed.

\section{Questions of the Study}

My current assignment is administrative; I am dean of a college that serves both undergraduate and graduate students. Two of the questions

From To Improve the Academy: Resources for Student, Faculty, and Institutional Development, Vol. 7. Edited by J. Kurfiss, L. Hilsen, S. Kahn, M.D. Sorcinelli, and R. Tiberius. POD/New Forums Press, 1988. 
that interest me are: How can we increase undergraduates' involvement in their own learning? and What are the most effective ways to promote research through graduate education? In the end, my classroom research project helped me focus on both of these challenges, although I did not see the connection clearly at the beginning of my project.

Initially, my project focused on this question: How do undergraduate students at our institution use their time? The question represents an operational attempt to learn more about student involvement in learning, a topic which has interested me for a number of years. To be involved in learning means, at least, to spend time on learning, to be engaged in activities that promote learning, to work on learning outside the class-room. After several years of reading the literature on student retention and student involvement in learning, I have been struck by how little we know about the time students spend in class, and about the time they spend studying, working on research projects, and otherwise engaged in the types of learning experiences we hope they have.

I investigated this question with a group of graduate students enrolled in a one-credit seminar. Thus, the subjects of my initial interest (undergraduates) were not the students in my class. While this may stretch the boundaries of classroom research, I also learned about my graduate students as learners and as beginning researchers through documentation of their work and recording of their own discussion of that work.

My interest in undergraduate student use of time as a way to gauge student involvement in learning goes back five years when I became one of several "special academic counselors," each matched with five freshman or sophomores whose academic dismissal was waived if they would participate in this then-experimental program. We who served were to work individually with these students, armed with some knowledge about student retention and with information about University services that might be helpful to them. We met with our students as often as seemed productive. Some students paid little attention to us; others became fast friends and would visit weekly.

Soon I began asking my students how they were spending their time. I drew a grid for them on a piece of paper: seven columns and twenty-four rows, representing 168 hours in a week. One intention was to reinforce a rule we solemnly tell students at orientation: They should expect to spend three hours of academic time per week for every credit they are taking (e.g., a three-credit lecture course would have three hours of lecture per week plus six hours of study time). In general, students had difficulty with this excrcise. Most needed prompts to think about how to fill out the grid. Some could not complete the exercise for the immediate prior week or 
for a "typical week this semester," and needed to be coaxed through keeping track of their time for a week at a time as they went.

This sort of primitive time-management investigation/tutoring raised questions for me: Were these students typical of our undergraduates in their use of time? I doubted it, since lack of time with their studies was clearly a problem for several of them; on the other hand, the published literature suggests that most students spend closer to one hour studying per hour in class than the two we hope for. Perhaps these students spend as much time studying but are less efficient at it or less well prepared on entry.

Were these students typical of our undergraduates in their (in)ability to easily describe their use of time or to plan how they would study? Are our over-achievers who do well academically and who also work and have outside activities more fluent in explaining their use of time? Are they more flexible in planning their time? Are our juniors and seniors more adept with their time?

The topic of student use of time continued to interest me. In these last years I have read a fair amount of the published literature on undergraduate students, and although I did not do a systematic search of the literature, I kept an eye out for research on student use of time. I found very little and none that I found satisfying.

\section{Method}

The class I worked with on this classroom research project was Issues in Higher Education, a one-credit class offered on an experimental basis to students in our master's degree program in higher education student personnel. Students in this program are preparing to work in student affairs divisions of colleges and universities, in settings such as admission, career services, learning assistance centers, student activities, financial aid, and residence halls. Most of the students are working on graduate assistantships in one of these offices on our campus. They are an energetic and engaging group of students and generally well-connected with many aspects of the lives of our undergraduates. The time study represented one-third of our work for the semester. Five students were enrolled in the class.

The graduate class seemed ideally suited to undertake the project: they were interested in undergraduate student life, had access to undergraduate students, were generally informed about aspects of undergraduate life mysterious to many faculty members, and were enrolled in a program that encouraged student research. 
We prepared for designing the study by reading and having a guest lecturer. The readings included three chapters from Boyer's College: The Undergraduate Experience in America, a few research studies on student use of time that the seminar students found in the published literature, and a short paper I drafted for them explaining why an institution would be interested in knowing more about how undergraduates spend their time. Our guest lecturer was Dr. Fran Noring, a faculty member whose academic preparation included work on time management and studies of time use in the home. She brought us several other articles and some chapters from a national time use study (Robinson, 1977). She conducted a session for us on various ways people conceive of the time available to them and ways in which time use is studied; she also joined us for some of the other class sessions that focused on this project.

The week before the class designed the data collection instrument we spent some time going over material I thought would be helpful to them. One topic was a review of levels of power of social science research, from description, to prediction, to control. These graduate students tend to work at a very practical level; the temptation is to turn a question of use of time into a question of teaching students time management. Since the research on typical time management "workshops" reports rather dismal results (e.g. Cranney \& Kirby, 1980), a study that would begin with a description of student use of time seemed to hold a promise of potential utility. The classroom challenge was to make the pay-off from "research" on time use seem interesting in itself while teasing students away from immediately practical ends.

In class we also reviewed various ways to study time use (e.g., time diary-yesterday/last week; time diary-tomorrow/next week; normal weekly schedule; estimates of time spent daily, weekly, monthly, or annually; and estimated frequencies). We ruled out as too expensive the most direct methods of studying undergraduate student use of time: following students around for a day or a week and recording their activities or giving students an electronic beeper set to go off at random times at which signal students would record their activity.

We talked about the research questions that such a study might address: How does the average student spend his or her time? Does that vary by gender, residence, year in school, grade point average, or major? What can we learn from students in trouble about their time use that might inform our programs to help them? Can time use describe different perceived subcultures of students, such as fraternity residents, adult students, athletes, engineers, commuters, and theatre majors? How do students spend their time in relation to our expressed hopes as an institution (e.g., Do they stay on campus for the weekend? Do they report attending cam- 
pus cultural events?) Do various realistic ways of gathering data give us equally useful and apparently valid indications of student use of time?

Finally, we discussed our realistic expectations for the study, including how these graduate students would benefit from conducting this cooperative investigation.

One class period of 90 minutes was spent designing the study. The graduate students were to design a study that would gather hour-by-hour time use data from individual undergraduate students along with some other information (such as demographic data) that they could use to help interpret the time use data. The graduate students designed the study; my role was to serve as a recorder of their decisions and as their "secretary," who would turn their decisions into instruments they could use for data gathering. During their discussion, I tried to be quiet, observing their work, summarizing when helpful, and making sure I had recorded their decisions. (I find being silent this much generally very difficult in the classroom, and I did speak up at three or four points.)

By the end of the class period, the students had decided to gather the following data from four undergraduate students each (one from a residence hall, a commuter from home, a commuter from "down the line," and a fraternity or sorority resident): a detailed recall of the prior $\mathbf{2 4}$ hour period; a description of time use, hour by hour between 6:00 AM and 2:00 AM for the prior seven days; and a brief demographic questionnaire (age range, gender, major, year in school, living arrangements, child care responsibilities). In addition to gathering the data, students were to write brief case studies on each undergraduate and a brief integrative paper. By the end of the discussion, it was clear that there were at least two major goals of gathering the data: 1) to learn more about how undergraduate students spend their time; 2 ) to gain some informed perspective on how to gather data on this topic.

\section{Results and Discussion}

What did I learn? Nothing startling and nothing definitive. But I have a sharpened sense of understanding on three topics that continue to intrigue me: 1) how undergraduate students spend their time; 2) how to gather data about that topic; and 3) how to work with graduate students who are beginning to conduct research.

Below are a couple of points from each of these topics, as illustrations.

Undergraduate Student's Use of Time. If the 20 students on whom we gathered data are representative of any significant portion of the stu- 
dent body, many of our students do not observe the two-hours-of-studyper-hour-in-class rule we tell them. Our informal data suggest that for many students a 1:1 correspondence is more descriptive.

Faculty members may think students don't do well in their classes because they enter without sufficient academic prepara-tion. Our data would suggest that for some students, at least, the problem is as likely to be the amount of time they devote to their studies as undergraduates. As a sometime teacher of un- dergraduate students, I suspect this problem is more difficult for faculty to deal with: It's easier to blame prior academic preparation than to admit that students aren't doing well in my class because for whatever reason they aren't working very hard at it. Prior preparation isn't my fault; current motivation may be. I do find clues that students aren't spending sufficient time working on my class material to be very discouraging; my conversations with other faculty members suggest to me that I am not alone.

Also, if these 20 students are in any way representative, our students seem to be spending less time working than current campus folklore might suggest, less time watching TV, and more time socializing. One student reported socializing 51 hours the prior week. Obviously, the sample may be biased, though several of the students in the sample were approached as they worked at their campus jobs. Less time watching TV than we suspect is obviously good news; more socializing is not. Since students made up their own descriptors when they recorded their time, what we counted as socializing included "with boy friend," "drinking," "hang around," "go out," and a variety of synonyms.

How to Gather Data on This Topic. As the graduate students designed their method, they discussed the advantages and disadvantages of gathering data from several students on how they spent one day versus gathering data from fewer students on how they spent a week. In the end, their opinions were mixed. Generally, the graduate students felt that having data on only one day would not be representative; they didn't feel they had an accurate picture of how a student spent his or her time by looking at only one day. However, a week is difficult for some students to remember. A few students just couldn't finish the task; others were described as "playful" in their approach to filling our our data collection sheets.

Several of the graduate students felt that they gathered data that were more candidly reported than a faculty member might have obtained. Generally closer in age to undergraduate students and not in positions of authority, the graduate students did generate descriptors of time use I doubt I would have received. (One undergraduate reported this sequence of five hours: arrested, released, drinking, drinking, drinking.) The 
graduate students' reports validated comments I had heard about our library. Time reported in the library may be either primarily study time or primarily social time. The difference is subtle, as some students head to the library with modest intentions of study but are easily distracted into socialization; these distractions are apparently easier to come by in certain sections of the library than in others. A devoted scholar can find quiet space in the library, and this activity is perhaps more likely to be reported as "research in library" than simply as "library."

Graduate Students as Beginning Researchers. This project was very useful to me as a way to think about involving graduate students in research. As the students designed their study in class, I was struck (again! I've seen this before) by how easily they focused on an instrument with which they would gather data and how difficult it was for them to focus on the question they wanted to study. One member of the class kept reminding the others that they needed a question to focus their inquiry. Her reminders, though not dramatically successful, helped to move the discussion beyond methodology. The graduate students arrived at what I felt was a reasonable method for their study, but I was not confident they all understood why it was reasonable or exactly what their study could hope to produce.

The graduate students generally had very little sense of themselves as researchers or the effect they could have on the outcome of the study. Some graduate students made clear observations of their undergraduate volunteers; others remarked that they gave the students the task and then turned to other duties, seemingly unaware of the opportunity they were missing for observation. In class we discussed how presentation of the task could influence the outcome of such a study; the graduate students seemed to take this as a new idea.

The data the students gathered were raw, and students varied in the degree to which they could summarize the data: from no useful summary directly related to the data; to a summary of hours per week devoted to specific areas; to a conceptual framework of time, with examples from the sample.

\section{Conclusion}

What did I learn? My two questions at the beginning were: How can we increase undergraduates' involvement in their own learning? and What are the most effective ways to promote research through graduate education? Certainly I did not find definitive answers to either question. However, what I learned helps me approach these two questions with bet- 
ter information. First, my belief in the usefulness of measuring time as a way of understanding involvement in learning was strengthened; knowing more about how students use their time will help faculty members and administrators understand the undergraduate experience and think about ways to improve it. However, I now think that measuring student use of time in ways that are meaningful and reliable will be more difficult than I had anticipated.

Second, if we want all graduate students to develop habits and skills of research-and I think we should-then I am more convinced than before that we need to involve them more frequently in research projects and activities that hone their research skills. (Generally, at the master's level, we say that we want students to become "intelligent consumers of research." I am more inclined to think that part of the process of becoming intelligent consumers is understanding the research process through experience.) These students did a very respectable job on their study. Perhaps because of their work in counseling and related courses, they were superb at working together to plan the study. They listened carefully to each other and built on what others had said. In this way they were models. It is clear, however, that we could have benefitted from more time in class discussing their process of gathering data, the influence of instrumentation and researcher, analyzing the data, and figuring out what next steps are called for in continuing the investigation. They need more practice in the skills and habits of research than we have been providing them.

\section{References}

Boyer, E.L. (1987). College: The undergraduate experience in America. New York: Harper and Row.

Cranney, A.G. \& Kirby, A.F. (1980). Time management in college. ERIC ED 203210.

Robinson, J.P. (1977). How Americans use time: $A$ social-psychological analysis of everyday behavior. New York: Praeger.

\section{Author Notes}

The assistance of Dr. Fran Noring (Human Development, Counseling, and Family Studies Department, University of Rhode Island) in presenting information on how people conceive of time and how researchers have studied its use is gratefully acknowledged. 